\title{
Research on Comprehensive Intervention and Quality Monitoring of Higher Vocational Labor Education in the New Era
}

\author{
Xie Gen-tan ${ }^{1, a}$, Sun Qing ${ }^{1, b}$, Bi Zhi-liic ${ }^{2 *}$ \\ ${ }^{1}$ Youth League Committee, Binzhou Polytechnic, Binzhou, Shandong, China \\ ${ }^{2}$ Academy of health, Binzhou Polytechnic, Binzhou, Shandong, China \\ axiegentan@126.com \\ b824566046@126.com \\ c*beelili@126.com
}

\begin{abstract}
The ways to carry out labor education in higher vocational colleges include setting up labor courses, professional characteristic training, labor practice week and participating in social practice, so as to cultivate higher vocational college students to establish good labor values and help them form effective labor behavior habits. Focusing on the achievement of labor education objectives, this paper analyzes the key factors affecting the achievement of labor education objectives, and constructs a comprehensive intervention and quality monitoring system of Higher Vocational Education in the new era of "credit + learning point, dynamic project, multi-dimensional synchronization and platform support" in Higher Vocational Colleges from the aspects of basic path, practical operation and control platform, Finally achieve the goal of labor education.
\end{abstract}

Keywords: Labor education, credits + learning points, dynamic project, multidimensional synchronization, platform support

\section{新时代高职劳动教育综合干预与质量监测研究 \\ 谢根坦 ${ }^{1, a}$ ，孙晴 ${ }^{1, b}$ ，毕智丽 ${ }^{2, c *}$}

${ }^{1}$ 滨州职业学院团委, 滨州, 山东, 中国

${ }^{2}$ 滨州职业学院健康学院, 滨州, 山东, 中国

axiegentan@126.com

b824566046@126.com

c*beelili@126.com

\section{摘要}

开展高职院校劳动教育的方式包括开设劳动课程、专业特色实训、劳动实践周、参加社会实践等，培养高职院 校大学生树立良好的劳动价值观念，助力养成有效的劳动行为习惯。本文围绕劳动教育目标的达成分析影响劳 动教育目标达成的关键要素，从基本路径、实践运行、管控平台方面，构建高职院校 “学分+学点、动态项目、 多维同步、平台支撑” 新时代高职劳动教育综合干预与质量监测体系, 通过各个要素建设实施方案的达成, 最 终实现劳动教育目标。

关键词: 劳动教育, 学分十学点, 动态项目, 多维同步, 平台支撑

作者简介：谢根坦 (1980一), 男, 河北冀州人, 讲师, 团委书记, 研究方向为职业教育。 
职业素养、职业认同、职业价值、核心素养养成等既

\section{1. 引言}

目前, 有关于高职院校为大学生开设劳动教育的 相关研究, 大多集中在对高职大学生劳动观形态的研 究 $^{[1]}$, 如何开设相关课程和相关活动项目的研究, 以 及宏观层面的相关系统研究等方面。然而相对于理论 层面, 则缺乏专项、系统、深入的有关研究, 对高职 劳动教育的效果如何保证质量的研究, 以及劳动教育 质量监测环节的专项研究, 这些研究类型的成果数量 均较少 ${ }^{[2]}$ 。

在此, 本研究团队首次提出对劳动教育质量监测 的操作方法, 将 “第一课堂” 与 “第二课堂” 相结合 的相关实施路径和有关成果, 在深挖平台建设的内 涵、外延、硬件、软件建设等方面均具有一定前沿性; 本研究团队以新的视角, 对劳动教育质量监测服务于 人才培养运行机制、提升高职大学生综合素养等进行 了有效探索。

\section{2. 新时代高职劳动教育研究现状及存在问题}

虽然当前关于开展大学生劳动教育的研究进行 得如火如茶, 研究角度和研究方法丰富多样, 但不足 之处也相对比较明显。例如, 国内有关劳动观教育的 方法和载体创新的研究还很少, 对国外研究成果和经 验的借鉴也比较少, 导致目前国内高职劳动教育相关 概念尚没有系统的明确界定 ${ }^{[3]}$, 而且在理论层面上, 对高职大学生劳动教育进行专项系统研究的成果数 量一直比较少 ${ }^{[4,5]}$ 。

本研究团队首先对高职大学生进行劳动教育过 程中普遍存在的问题进行了梳理, 并根据梳理出的问 题, 进一步基本理清了对高职劳动教育的开展有影响 作用的因素, 初步构建出高职劳动教育的目标, 并制 定了相关标准。再通过运行中出现的新问题, 继续对 国内高等职业院校劳动教育现状进行广泛调研, 进一 步找准核心问题。

\section{3. 高职劳动教育综合干预与质量监测研究}

在前期找到高职劳动教育开展的核心问题的基 础上, 本研究团队通过调查接受相关劳动教育的学生 们对核心问题的反馈, 进一步修改系统实施方案, 明 确学生对劳动教育的核心诉求, 找准核心问题改进目 标。通过调研、中期数据平台分析, 进一步改进标准, 提升劳动教育质量。

\section{1 建立 “学分+学点” 劳动教育人才培养方 案}

国家职业教育规划中明确提出, “探索建立适应 弹性学习、学分制和主辅修制的教学管理制度”。各 高职院校除了通过正常人才培养方案中的实施计划, 开设进行的专业实习、实训、见习、实验等教学安排 之外, 还可在各种课程的授课内容中融入工匠精神、 属于课程思政, 又属于劳动教育的专题教育内容, 并 设置开设课时要求不少于 20 学时, 配套设置相应“学 分”; 另外, 还可结合高职大学生的校内劳动实践周 进行劳动专项教育，在课余时间、周末、小长假、寒 暑假等假期期间开展社会实践活动等，并配套设置相 应的 “学点”, 以促使各高职院校的大学生们将劳动 行为习惯有效养成 ${ }^{[6]}$ 。

首先, 通过探索构建高职院校劳动教育质量指标 体系, 来探索劳动教育的弹性学习机制, 以 “学分+ 学点” 的配比来完善人才培养方案, 并纳入对学生毕 业的要求。并在劳动教育的具体教学实施过程中, 利 用 “教务教学” 平台 + “到梦空间” 平台的协同作 用, 建立实时数据的监测、预警和改进等的综合评价、 监测系统。

其中的 “学分” ，即根据各学科、各专业的不同 特点, 以及各自不同的育人目标, 将劳动教育有机融 入各种课程的教学实践之中, 将劳动教育的学习成效 融入到学生的 “修学分” 过程当中。一方面, 在开发 劳动教育相关课程的过程中，可以采用阶梯式的方法 来设计能力目标，例如以服务性劳动与创新创业项 目、生产劳动与创新创业项目等, 项目化阶梯递进式 的课程, 学生完成课程目标即可获得学分。另一方面, 可以设置限定选修课, 例如日常生活劳动技术及创新 课程、服务性劳动与创新创业课程、生产劳动与创新 创业课程等, 完成课程学习通过考核后, 即可给予学 生相应学分。

所谓 “学点”，即结合 “到梦空间” 平台，定期 或不定期地设计并发布劳动教育活动项目，并做到形 式多样、动态管理, 高职大学生们通过自主选择感兴 趣的活动项目, 线下参与活动, 可以大大提高活动参 与率、完成率与好评率, 完成效果也更佳, 最后或通 过学生之间的互评, 或由指导教师根据学生参与活动 的情况打分, 学生即可获得相应学点。通过完成有关 课程的学习, 及相应活动项目的参与, 学生可以获得 相应的 “学分十学点”, 即可全方位考核学生综合的 劳动素质能力。

\section{2 构建劳动教育线上管理平台}

根据教育部《关于建立职业院校教学工作诊断与 改进制度的通知》要求, 高职院校要积极推进 “高等 职业院校人才培养工作状态数据采集与管理平台” (简称 “状态数据平台” ) 的建设和运用, 本研究团队 应用 DM 技术，借助 “教务管理平台” 和 “第二课堂 管理平台”，发挥其在宏观管理、教学改革、质量提 升、年度报告、用户画像中的基础性作用。在此背景 和基础之上，进一步协同实现劳动教育管理的制度 化、规范化和标准化，有效促进了人才培养质量的不 断提升。这些效果都是通过深挖以上各平台的硬件、 软件、内涵、外延来共同实现的。高职院校还可以通 过网络管理系统云存储的大数据, 监测各门课程进展 
和各种项目的动态，并能及时做出调整，合理化时间 分布情况, 还可以监测学生劳动时长, 以及跟踪学生 对评价的反馈情况等。

\section{3 完善劳动教育质量监测体系}

质量监测模型的设计是基于 “ $\mathrm{PDCA}$ 循环” 、 “SWOT 分析模型”、“质量改进螺旋” 等先进的质量 管理理论。本研究团队通过横向调研、纵向比对, 开 展研讨制订监测标准 ${ }^{[7-9]}$, 以 “策划一实施一检查一 改进” 为实现的工作循环, 确定劳动教育具体项目的 教学目标、设计质量标准、制定教学计划、组织教学 项目资源、实施实践教学, 并通过平台数据分析、学 习效果总结、改善人才培养方案, 及相关标准的制定。 进行过程化监测, 监测发现问题时能及时预警, 再通 过问题的反馈、改进, 进一步优化标准和计划, 优化 实施方案, 从而构建起质量监控基本流程, 保障劳动 教育开展的效果与质量 ${ }^{[10]}$ 。

而对质量监测实施路径的构建, 需要理清质量监 测内部质量体系架构基本要素的内涵、内外部关系和 运行机制原理等内容。本研究团队从具体劳动教育项 目的劳动目标、劳动标准、机制体制、实施途径、实 施效果等多个维度进行监控 ${ }^{[11]}$, 通过运行一反馈, 构 建 “需求库” + “动态项目”, 以 “劳动时长” + “多 种类型” + “劳动成果评价”, 作为评价指标, 以保 证劳动教育的质量可以得到稳步提升。同时, 明晰项 目实施各方 “权责利” 的关系, 构建相互协同的有效 工作机制; 建立课程教学资源——动态项目需求库; 构建劳动教育实践场所, 满足多样化劳动实践需求; 完善评价、反馈、激励等配套机制, 综合各个方面, 最终可以收获相对完善的高职劳动教育质量监测体 系。

\section{4 构建劳动教育实施路径}

首先, 构建 “学分+学点、动态项目、多维同步、 平台支撑” 体系的具体实施路径, 需要基于相对完善 的管理平台，以过程化监测和及时预警的运行机制， 及时动态改进劳动教育的目标和标准, 进而改进高职 劳动教育项目实施方案, 即可形成监测闭环。其次, 以构建高职劳动教育质量指标为目的进行探索的弹 性学习制度, 以 “学分+学点” 的运行机制, 完善高 职院校各专业的人才培养方案, 并纳入对学生毕业条 件的要求之一。最后, 建立高职劳动教育课程相对完 善的教学体系, 形成 “学分” 基础劳动教育课程、

“学分” 专业技能型劳动教育课程、“学分” 劳动教 育选修课程, 以及 “学点” 项目劳动教育课程等, 这 样才能使得层层递进的高职院校劳动教育课程体系, 最终真正形成劳动教育学分体系、课程体系、考核体 系等较完善的系统。

动态项目一般需要根据劳动教育的 “能力目标一 类别统筹一项目匹配” 来进行制定。这需要以高职大 学生的长远发展需求为标准, 来构建劳动教育项目的
动态需求库，通过 “六横三纵” 的分阶段课程及动态 项目供给，精准对接高职大学生的能力提升。以 “劳 动时长” + “多种类型” + “劳动成果” 等多维的形 式, 依托 “教务教学” 平台+ “到梦空间” 平台, 建 立相应模块的对应管理平台, 进行实时数据的监测、 预警和改进的管理系统。

\section{4. 劳动教育综合干预与质量监测创新之处}

\section{1 研究视角的创新}

本研究团队从高职劳动教育工作开展中的综合 实施、反馈干预和质量监测等全视角切入，全面、系 统地考察分析了高职院校开展劳动教育的现状、体系 构建、培养路径、实施方法等方面, 目前普遍存在的 问题, 这在相关研究中属于较为新颖的研究体系与研 究结果。

\section{2 研究方法的创新}

本研究团队一方面选择了定量研究的方法, 这适 合从宏观层面进行大规模调查和预测; 同时还选择了 质性研究的方法, 则是可以通过与高职大学生的高频 互动, 了解他们对所接受劳动教育的看法、想法和感 受，同时对其劳动观的 “质” 可以得到一个比较全面 的把握。两种方法相结合, 更能够比较真实、客观、 有效地展示出高职大学生的劳动观和高职院校开展 劳动教育的现状, 为提出针对高职大学生劳动教育的 对策, 提供了非常有参考价值的依据。

\section{3 研究内容的创新}

本研究团队首次提出了 “第一课堂” 与 “第二 课堂” 相结合的高职劳动教育相关实施路径, 并取得 了一定的研究成果, 一系列的成果在深挖平台建设的 内涵、外延、硬件、软件建设等方面均具有较好的前 沿性; 并以新的视角对劳动教育质量监测服务于人才 培养运行机制、提升高职大学生综合素养等方面, 均 进行了深入探索。

\section{5. 结语}

在经济发展新常态的社会背景下，高职教育起到 了为未来经济建设培养建设者和接班人的艰巨任务。 因此, 高职院校创新劳动能力素质的教育教学, 决定 了高职大学生是否能够具备可持续发展的综合能力 和内生动力。

本研究团队开发的管理平台, 可以以“中心经 营” 的模式推广到其他相关高职院校共用。该项目还 将为其他开展劳动教育的高职院校提供可选择的模 式和具体对策, 具有广阔的推广空间, 帮助各高职院 校开展劳动教育的工作以适应新变化、解决新问题、 把握新规律。 


\section{项目基金}

本文为以下基金项目的阶段性成果： 1 . 滨州职业学院科研项目《新时代高职劳动教育 综合干预与质量监测研究》 ( 编号 : 2020YJKT36), 主持人：谢根坦; 2. 滨州职业 学院教学改革研究项目《“学分+学点、动态项 目、多维同步、平台支撑” 新时代 “青马工程” 培训班课程体系构建研究》(编号: xy jg2122), 主持人: 谢根坦; 3 . 滨州职业学院科研项目《性 别差异对高职生职业认同感影响及对策的分 析研究- - 以护理专业为例》(编号: 2017YJKT12), 主持人: 毕智丽; 4. 滨州市 2022 年度社会科学规划课题职业教育研究专项《高 职学生规则意识的培育研究》(编号: 22-ZJZX-04), 主持人: 毕智丽; 5. 滨州市 2022 年度社会科学规划课题思政教育专项《“多维 同步、平台支撑” 融入式培育体系对提升青年 马克思主义培养质量路径的研究》(编号: 22-SZZX-21), 主持人: 谢根坦。

\section{REFERENCES}

[1] Zheng, Y. F. (2016) A study on the education of "post-90S" college students, outlook on labor. Doctoral dissertation of Southwest Jiaotong University.

[2] $\mathrm{Li}, \mathrm{P}$. (2020) Research on examination and evaluation of higher vocational labor education. People's Tribune, 10:112-113.

[3] Jiang, L.J. (2019) Analysis and practice of labor education concept in higher vocational colleges.
China Higher Education Research, 02: 78-81.

[4] Li, K., Qu, X. (2018) Historical evolution and reflection of labor education in the party's education policy since 1949. Journal of Educational Studies, 14(05): 63-72.

[5] Liu, Y. H. (2019) Pluralistic integration: a new perspective of school labor education. Jiangsu Education, 26:13-14.

[6] Wang, Q. (2020) Practice and exploration of labor education course in higher vocational colleges. Tea in Fujian, 42(04):200-201.

[7] Zhang, X., Yuan, Y. Z., Li, H. B. (2019) International experience of labor education and its enlightenment. Journal of Teaching and Management, 11:56-58.

[8] Zhang, R.R. (2018) Research on the education of Chinese Youth's Concept of Labor in the New Era. 05 .

[9] Patrick, N. Foster. (1997) Lessons from history: industrial arts/ technology education as a case. Journal of Vocational and Technical Education, 13(02).

[10] Zhang, Y., Chen, G. X. (2017). Research on entrepreneurship education in higher vocational colleges -- taking the foundation and practice of college students' entrepreneurship as an example. Occupation, 31:126-127.

[11] Liu, Y., Hu, X. K. (2018) Research on social practice in colleges and universities. Western China Quality Education, 4(12):37-38. 